\title{
ANÁLISE DA EXPOSIÇÃO AO OFUSCAMENTO E À INSOLAÇÃO EM AMBIENTE DE USO PROLONGADO
}

\section{Analysis of occupants' exposure to daylight glare and insolation inside prolonged use room}

\author{
Dayan de Loyola Ramos Garcia ${ }^{1}$ \\ Universidade Federal de Santa Catarina, Florianópolis, SC, Brasil, dayan@labcon.ufsc.br \\ Fernando Oscar Ruttkay Pereira ${ }^{2}$ \\ Universidade Federal de Santa Catarina, Florianópolis, SC, Brasil, ruttkay.pereira@ufsc.br
}

\begin{abstract}
Resumo
Ocupantes expostos à radiação solar indesejada e a brilhos e contrastes excessivos, quando em ambiente de uso prolongado, vivenciam desconforto térmico ou visual e consequentemente reagem alterando as características de sua ocupação ou do sistema de iluminação natural mais comum: a janela. Neste contexto, essa pesquisa se objetivou em identificar e relacionar os níveis de probabilidade de ofuscamento e de radiação solar incidente para um ocupante em uma sala de permanência prolongada. A partir da modelagem e simulação computacional da irradiação solar, os valores horários dos indicadores de ofuscamento e insolação foram transformados em frequências e perfis anuais. Dentre as frequências anuais de ofuscamento, se atingiram diferenças de até $74 \%$, advindas da mudança de $90^{\circ}$ na direção de visão. As frequências de radiação solar direta maior que $50 \mathrm{~W} / \mathrm{m}^{2}$ apontaram vulnerabilidade, em cerca de $1 / 5$ do tempo de uso, para ocupantes a 1,5 m da abertura, nas orientações Norte, Leste e Oeste. Os perfis anuais de probabilidade de ofuscamento e de radiação solar incidente permitiram identificar as horas do dia e os meses do ano em que há necessidade de controle solar. Correlações lineares realizadas entre valores horários de DGP (Daylight Glare Probability) e de radiação solar resultaram em grau $\left(R^{2}\right)$ abaixo do significativo, porém permitiram demonstrar a influência de cada componente no desconforto visual apurado. As 60 combinações investigadas de posições (03), direções de visão (05) e orientações solares (04) foram discriminadas com relação à exposição excessiva e assim agregaram recomendações de projeto que previnem os ocupantes do ofuscamento e da insolação.
\end{abstract}

Palavras-chave: Ofuscamento. Insolação. Simulação computacional. Desconforto visual.

\begin{abstract}
Occupants at side-lit rooms used daily, when exposed to undesired solar radiation and excessive brightness and contrast, experience thermal or visual discomfort and consequently react by changing the occupation and window's characteristics. In this context, this research aimed to identify and relate daylight glare probability and incident solar radiation to an occupant in a prolonged stay room. From the modeling and computational simulation of solar irradiation, hourly glare and sunshine indicators were transformed into frequencies and annual profiles. Among the annual glare probability's frequencies, differences up to $74 \%$, were observed, due to the $90^{\circ}$ change in the vision direction. Frequencies of direct solar radiation greater than $50 \mathrm{~W} / \mathrm{m}^{2}$ indicated vulnerability, at about $1 / 5$ of time of use, to occupants $1.5 \mathrm{~m}$ from the opening in the North, East and West orientations. Daylight glare probability and incident solar radiation's annual profiles allowed identifying the hours through the day and the months through the year in which solar control is needed. Linear correlations between hourly DGP (Daylight Glare Probability) and solar radiation's values resulted in an insignificant degree level $\left(R^{2}\right)$ but allowed to demonstrate the influence of each component on the visual discomfort. The 60 investigated combinations of positions (03), vision directions (05) and solar orientations (04) were discriminated in relation to excessive exposure and thus added design recommendations that prevent occupants from daylight glare and direct sunlight.
\end{abstract}

Keywords: Daylight-glare. Direct-sunlight. Computational simulation. Visual-discomfort.

How to cite this article:

GARCIA, Dayan de L. R.; PEREIRA, Fernando O. R. Análise da exposição ao ofuscamento e à insolação em ambiente de uso prolongado. PARC Pesquisa em Arquitetura e Construção, Campinas, SP, v. 11, p. e020004, 2020. ISSN 1980-6809.

DOI:http://dx.doi.org/10.20396/parc.v11i0.8654565 


\section{Introdução}

Maximizar a sensação de bem-estar e produtividade e atender as preferências visuais dos ocupantes de edifícios iluminados pela luz natural são desafios que arquitetos, engenheiros e projetistas de iluminação enfrentam, enquanto buscam não deixar de lado a eficiência energética da edificação (VAN DEN WYMELENBERG; INANICI, 2014; KONIS, 2014; SUK; SCHILER; KENSEK, 2013; GALASIU; VEITCH, 2006). A radiação solar é energia que se relaciona com a arquitetura das edificações manifestando-se na forma de luz e calor no ambiente. Como anunciado por Carletti, Sciurpi e Pierangioli (2014), principalmente em edifícios de múltiplos pavimentos, as janelas são os sistemas de iluminação natural mais empregados e desempenham importantes funções nos aspectos térmicos, lumínicos, acústicos, estéticos, dentre outros.

Stazi et al. (2014) apontam que uma das funções mais almejadas no projeto dos sistemas de abertura é integrar os desempenhos térmico e lumínico, que em algumas situações, podem ser conflitantes. Matos e Scarazzato (2017) ressaltam que manter o contato visual com o exterior e dar preferência à luz natural ao custo de admitir calor solar indesejado é exemplo destes possíveis conflitos. Esta situação é presente principalmente em regiões de climas quentes, como no Brasil. Segundo O'Brien, Kapsis e Athienitis (2013) e Van Den Wymelenberg (2012) a inserção de elementos de controle solar em ambientes de permanência prolongada se decorre principalmente pela incidência de radiação solar direta e pelo desconforto visual por brilhos ou contrastes excessivos, fenômeno intitulado como ofuscamento.

No entanto, investigações computacionais e de campo, como Wienold e Christoffersen (2006), Jakubiec e Reinhart (2012) e Goedert (2017), evidenciam que o posicionamento do ocupante e o direcionamento de seu campo visual são fatores que, além de se relacionarem com o lay-out interno das edificações, influenciam substancialmente na percepção visual. As reações dos usuários com relação à posição ocupada, à direção de visão em seu posto de atividade e ao uso de elementos de controle solar na janela possibilitam adaptações em situações desconfortáveis.

A perspectiva da modelagem e da simulação computacional dinâmica da insolação é utilizada por diversos autores em conjunto com validações de campo (KONSTANTZOS; TZEMPELIKOS, 2017; JAKUBIEC; REINHART; VAN DEN WYMELENBERG, 2015; KARLSEN et al., 2015; REINHART; RAHKA; WEISSMAN, 2014). Esta abordagem computacional possibilita com maior facilidade a continuidade de investigações envolvendo localidades e propriedades físicas ainda não estudadas. Estas ferramentas consolidadas são inseridas na prática de projeto e em normas técnicas. Com esse embasamento, erguese motivação em investigar as implicações do comportamento da luz solar em interiores, com o intuito de apurar condições desconfortáveis e indicar alternativas de controle deste recurso natural. Neste contexto, o objetivo da pesquisa é identificar e relacionar os níveis de probabilidade de ofuscamento e de radiação solar incidente para um ocupante em um ambiente considerado de permanência prolongada.

\section{Fundamentação}

Como relatado por Goulart (1997), as janelas contextualizadas em meio aos modelos e materiais garantem ventilação, iluminação natural, privacidade, vista exterior, espacialidade ao ambiente, conhecimento sobre o tempo e hora do dia, dentre outros benefícios. Collins (1975) e Markus (1967) exploram a satisfação dos usuários quanto a estes fatores e ressaltam que recomendações projetivas de edificações e de proteções solares devem levar em conta o desejo e o julgamento do usuário, especialmente pelos raios solares, privacidade e contato visual com o exterior. 
Através de entrevistas que registravam a reação e a resposta dos ocupantes de diversas edificações, Ne'eman (1974) expõe que a aceitação ou a rejeição dos raios solares pelos ocupantes pode ser baseada no clima local, mas que sofre influência evidente das atividades e das posições das pessoas no interior do ambiente.

Os estudos e as normas sobre admissão de luz natural têm prescrito a medição e a avaliação de iluminâncias no plano horizontal de desempenho das tarefas visuais, como ler e escrever (0,7 m-0,8 m). Entretanto, as iluminâncias verticais monitoradas à altura da face do observador têm sido empregadas em avaliações relacionadas ao desconforto visual por excesso de brilho ou contraste em ambientes iluminados pela luz natural (ABNT, 2005a; ABNT, 2013; MARDALJEVIC; HESCHONG; LEE, 2009).

Desconforto visual por ofuscamento

O desconforto visual por excesso de brilho e contraste diante do campo visual do observador, chamado também de ofuscamento, pode atingir níveis desconfortáveis que ao decorrer do tempo implicam em reações de controle dos usuários e níveis intoleráveis que imediatamente desabilitem o ocupante no desempenho de suas tarefas visuais (HOPKINSON, 1972; RUBIN; COLLINS; TIBBOTT, 1978; CHAUVEL; COLLINS; DOGNIAUX, 1982; WIENOLD; CHRISTOFFERSEN, 2006).

A luminância $\left(\mathrm{cd} / \mathrm{m}^{2}\right)$ é a grandeza fotométrica que representa o brilho. Esta tem se mantido no decorrer dos métodos científicos atuais por demonstrar forte relação com a sensação de desconforto reportada pelos ocupantes, enquanto a iluminância horizontal tem resultado em fraca relação com o ofuscamento (WIENOLD; CHRISTOFFERSEN, 2006). Contudo, como ressaltam Van Den Wymelenberg e Inanici (2014), ainda falta consenso e confiabilidade entre a comunidade científica e projetistas sobre quais métricas e quais critérios devem ser utilizados. Sendo o índice de desconforto uma avaliação numérica feita a partir da distribuição de luminâncias no campo de visão em determinado momento, prognosticar a manifestação de desconforto visual por meio de imagens especializadas tem se tornado uma maneira confiável de realizar inferências de situações indesejadas (REINHART, 2018).

Wienold e Christoffersen (2006) elaboraram o índice "Daylight Glare Probability" (Equação 1 e Tabela 1) a partir de estudos com pessoas em 72 espaços na Dinamarca e Alemanha. Dados medidos e calculados resultaram em melhor correspondência deste índice em relação aos anteriores, decorrente deste considerar a presença do sol no campo visual.

$$
D G P=5,87 * 10^{-5} * E_{v}+9,18 * 10^{-2} \log \left(1+\sum_{i} \frac{L_{s, i}^{2} * \omega_{s, i}}{E_{v}^{1,87} * P_{i}^{2}}\right)+0,16
$$

Onde,

DGP = índice "Daylight Glare Probability"

Ev = iluminância vertical no nível do olho [lx];

$L s=$ luminância da fonte $\left[\mathrm{cd} / \mathrm{m}^{2}\right]$;

$\omega s$ = ângulo sólido entre ponto do observador e fonte [steradianos];

$\mathrm{Pi}$ = índice de posição, entre fonte e observador (Guth Position index);

Tabela 1 - Valores de DGP e níveis de percepção de ofuscamento

\begin{tabular}{cccc}
\hline & \multicolumn{4}{c}{ Níveis de Probabilidade de Ofuscamento } & \\
\hline Imperceptível & Perceptível & Desconfortável & Intolerável \\
\hline DGP $<0,35$ & $0,35<\mathrm{DGP}<0,40$ & $0,40<\mathrm{DGP}<0,45$ & DGP $>0,45$ \\
\hline
\end{tabular}

Fonte: Wienold e Christoffersen (2006). 
A partir de imagens geradas por softwares, chamadas de visualizações ou renderizações (LARSON; SHAKESPEARE, 1998), passou a ser possível a obtenção de valores de DGP para situações em edificações ainda não construídas (JAKUBIEC; REINHART, 2012). Como demonstrado na Figura 1, softwares como o RADIANCE (MCNEIL; LEE, 2012) implementaram ferramentas de avaliação de brilho a partir de renderizações. Esta avaliação pode ser aplicada para cada hora do ano e isto embasa o chamado perfil anual de probabilidade de ofuscamento. Este perfil exibe as horas do dia e os meses do ano, como demonstrado na Figura 2. Entretanto, o maior problema em aplicar o DGP em avaliações dinâmicas da luz natural é o tempo e o recurso computacional requerido para o cálculo das imagens. Isto decorre porque a rotina de simulação anual é originalmente utilizada para cálculos pontuais de luminâncias e iluminâncias, não para imagens.

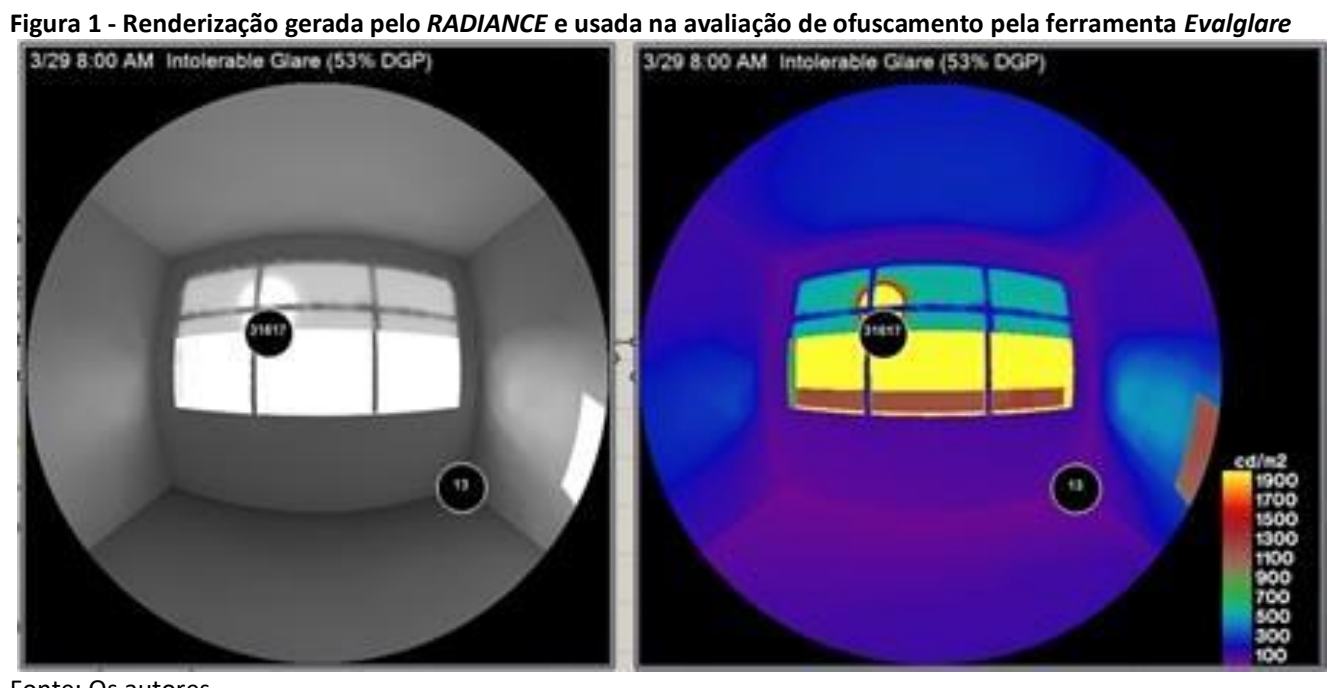

Fonte: Os autores.

Figura 2 - Exemplo de perfil anual de probabilidade de ofuscamento

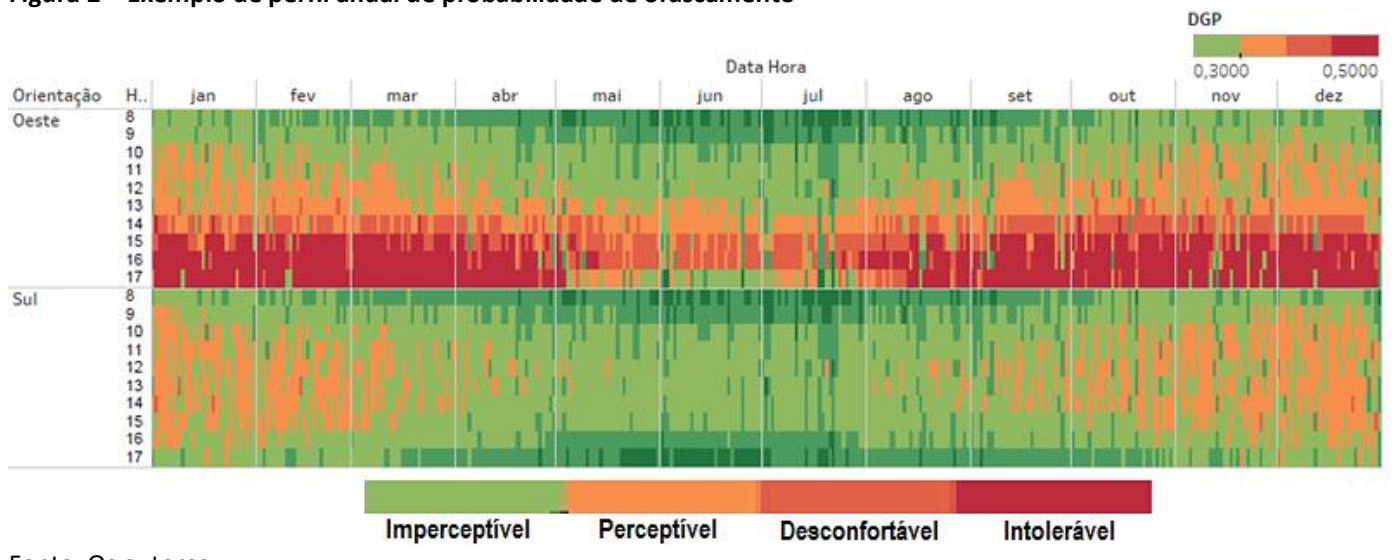

Fonte: Os autores.

A recente norma europeia "CEN Daylight Standard" EN 17037:2017 propõe tolerância de $5 \%$ de frequência anual de DGP excessivo para ambientes de trabalho. Três níveis de proteção contra o excesso de brilho são recomendados: Mínimo (DGP excessivo $>0,45)$, Médio (DGPexcessivo $>0,40$ ) e Máximo (DGP excessivo $>0,35)$. Konstantzos e Tzempelikos (2018) também adotaram tolerância de $5 \%$, pois ressaltam que em estudos de campo realizados em ambientes de escritórios, observou-se que, acima de 5,25\% do tempo de ocupação com DGP>0,40, ou iluminância direta no plano de trabalho maior que $1000 \mathrm{~lx}$, é provável que o ocupante esteja submetido a condições consideradas intoleráveis. 


\section{Insolação indesejada}

A presença indesejada dos raios solares no ambiente interno é considerada uma das principais causas de desconforto visual e térmico e culmina no desuso dos espaços vulneráveis ou na implantação de elementos de controle solar nas janelas (VAN DEN WYMELENBERG, 2014).

Newsham (1994) propôs um algoritmo de controle de persianas, no qual elas são manualmente abertas ao início do dia de trabalho e fechadas a partir do momento que o ocupante é atingido com insolação maior que $233 \mathrm{~W} / \mathrm{m}^{2}$. Entretanto, o algoritmo "Lightswitch-2002" proposto por Reinhart (2004) e recentemente empregado em ferramentas de simulação de edificações, indica como gatilho de controle de persianas a radiação solar direta de $50 \mathrm{~W} / \mathrm{m}^{2}$ incidente no plano da tarefa. Esses e outros valoresalvos de radiação solar direta incidente são discutidos na comunidade científica para melhor representar a insolação indesejada e embasarem algoritmos de controles manuais e automáticos de sistemas dinâmicos de iluminação natural (VAN DEN WYMELENBERG, 2012).

A Norma norte-americana “LM-83" (IESNA, 2012) propõe a avaliação lumínica de ambientes de escritórios de acordo com a autonomia de iluminação natural e a exposição excessiva do ambiente à luz solar direta. Esta norma discute que a exposição do plano horizontal à iluminância direta superior a 1000 lx representa melhor a presença de luz solar direta, em termos do desconforto visual, enquanto que nas simulações térmicas a radiação de $50 \mathrm{~W} / \mathrm{m}^{2}$ é correspondente à incidência de $4000 \mathrm{~lx}$. Também é embasado na norma que a incidência direta de $1000 \mathrm{~lx}$ por mais de $250 \mathrm{~h} / \mathrm{ano}$ confere ao local monitorado a característica de exposição solar anual excessiva. No entanto, falta consenso nas relações entre valores de radiação solar direta e iluminâncias.

Projetar edifícios é um desafio decorrente das diferentes necessidades e tolerâncias que cada indivíduo possui e devido às incertezas associadas ao uso de controles ambientais, como dispositivos de sombreamento e interruptores de luz artificial. Segundo Yao (2014), para reduzir o consumo de energia nas edificações enquanto se mantém o conforto visual e térmico, é crucial aplicar medidas eficientes de proteções solares. Logo, é crucial identificar e compreender a vulnerabilidade dos ocupantes à insolação indesejada e ao ofuscamento ao longo do espaço projetado e do tempo de uso, para com isto propor as melhores alternativas de lay-out interno e controle solar.

\section{Método}

A pesquisa possuiu abrangência exploratória e suporte de registro bibliográfico. Através da abordagem hipotético-dedutiva, utilizou-se método de procedimento comparativo e meios quantitativos de tratamento dos dados. Embora a investigação seja nãoparticipante em relação aos sujeitos, ela é considerada aplicada à sociedade. Os procedimentos foram compreendidos nas etapas de determinação das condições ambientais, escolha das características do envelope e da ocupação, simulação da probabilidade de ofuscamento e da radiação solar incidente e análise dos resultados.

A investigação proposta se limitou em não variar alguns parâmetros. Foi delimitada uma latitude em que ocorre menor altura solar nos meses do inverno. Foi considerado vidro simples e admitida ausência de obstrução do entorno para fundamentar uma condição de alta vulnerabilidade. A área de janela na fachada (PAF) foi limitada em um valor intermediário, indicando maior vulnerabilidade para valores maiores. A mobília interna não foi considerada para não afetar a distribuição da luz e para possibilitar trabalhar o lay-out a partir dos resultados dessa pesquisa. Outra limitação se estabeleceu nas quatro orientações solares adotadas: Leste, Oeste, Norte e Sul. 


\section{Condições ambientais consideradas}

Para analisar o comportamento da luz solar no interior de um ambiente, são estabelecidas informações da localidade adotada para a edificação. $O$ "EnergyPlus Weather Format" (EPW) é uma forma validada para representar as condições climáticas, baseada em médias de séries históricas (DOE, 2020). Também chamado de Arquivo Climático, nesse arquivo vêm listados para cada hora do ano (8760 horas) valores de radiação solar global, direta e difusa, dentre outras variáveis.

Como dados de entrada das condições ambientais foi adotado o arquivo EPW de Florianópolis - SC, elaborado pelo projeto SWERA (DOE, 2020). O arquivo climático desta cidade é situado na latitude de $-27,66^{\circ}$, longitude de $-48,55^{\circ}$ e altura de $5 \mathrm{~m}$ em relação ao nível do mar. Com base na norma de Desempenho Térmico de Edificações, NBR 15220 (ABNT, 2005), a cidade se insere na Zona Bioclimática 3 (ZB3) e possui classificação climática de Koppen como subtropical úmido. Analisando arquivo climático de Florianópolis, na Figura 3 é possível observar a variação das médias mensais da radiação solar global, difusa horizontal e direta normal.

Figura 3 - Radiação solar mensal média: global, difusa e direta em Florianópolis

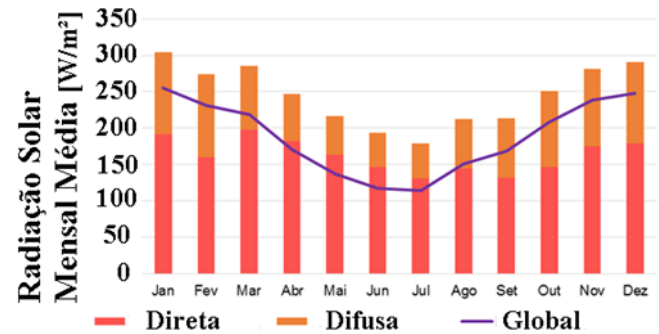

Fonte: Os autores.

\section{Características da envoltória e da ocupação}

As informações sobre a geometria do modelo de referência foram embasadas por Reinhart, Jakubiec e Ibarra (2013). O modelo é proposto para investigações lumínicas e considerado nesta pesquisa como ambiente de permanência prolongada e módulo de um edifício de múltiplos pavimentos, utilizado para sediar o desempenho de atividades visuais significativas, como ler e escrever. Mediante essas características de uso e de sua geometria simplificada, este ambiente é potencialmente representativo de edifícios encontrados no Brasil e no mundo.

O modelo de referência constitui-se de uma sala com dimensões internas de 3,6 $\mathrm{m}$ de largura, 8,2 m de comprimento e 2,8 $\mathrm{m}$ de pé direito (Figura 4). Possuindo área de 29,52 $\mathrm{m}^{2}$, este ambiente conta com uma fachada externa, na qual se localiza uma abertura envidraçada de 3,0 $\mathrm{m}$ de largura por 1,5 $\mathrm{m}$ de altura, com peitoril de 1,0 $\mathrm{m}$, resultando em $45 \%$ de área de abertura na fachada (PAF) e 15,4\% de relação entre área de janela e área de piso. Este PAF é usualmente encontrado em edificações brasileiras por ser um valor comedido e plausível para esquadrias comercializadas.

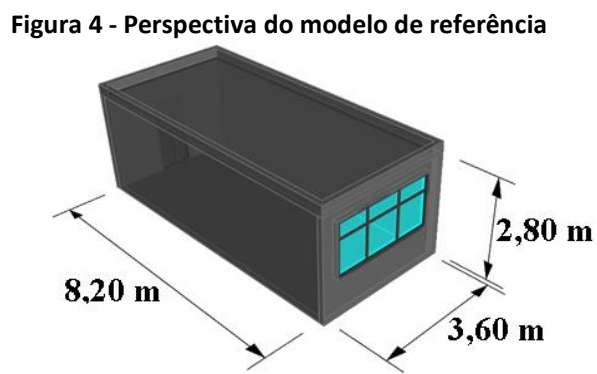

Fonte: Os autores (Elaborado no Rhinoceros 3D 5.0 através do arquivo referência). 
O envelope adotado na simulação da luz natural necessita considerar, além da geometria e da orientação solar, as propriedades térmicas e ópticas dos materiais, tais como as refletâncias dos componentes opacos em conjunto com as refletâncias e transmitâncias dos elementos translúcidos. Com base nos valores utilizados no modelo original, foram delimitadas para essa pesquisa as propriedades listadas na Tabela 2.

\begin{tabular}{|c|c|}
\hline Componentes do Envelope & Propriedades térmicas e ópticas \\
\hline Vidro claro comum $6 \mathrm{~mm}$ & $\tau_{\text {vis }}=88 \%$; Fator Solar $=0,82 ;$ Transmitância térmica $=5,8 \mathrm{~W} / \mathrm{m}^{2} \mathrm{~K}$ \\
\hline Paredes Internas & $50 \%$ de refletância difusa. \\
\hline Parede Externa & 35\% de Refletância difusa. \\
\hline Teto & $80 \%$ de refletância difusa. \\
\hline Piso & $20 \%$ de refletância difusa. \\
\hline Albedo & $20 \%$ de refletância difusa. \\
\hline
\end{tabular}

Fonte: Os autores.

Quanto ao padrão de uso atribuído ao ambiente em questão, este é ocupado diariamente das 8 hoomin às 17 hoomin, resultando em 3650 horas de ocupação. Foram monitoradas 03 posições para o ocupante ao longo da profundidade do ambiente, distando 1,5 m, 3,5 m e 6,0 m da janela. Em cada posição foi estabelecido que o ocupante se encontra sentado e com o direcionamento do seu campo visual para 05 direções estipuladas, como mostrado na Figura 5 . Nas 03 posições, a face do ocupante se localiza a $1,4 \mathrm{~m}$ do piso e o plano horizontal da tarefa a $0,8 \mathrm{~m}$ do piso.

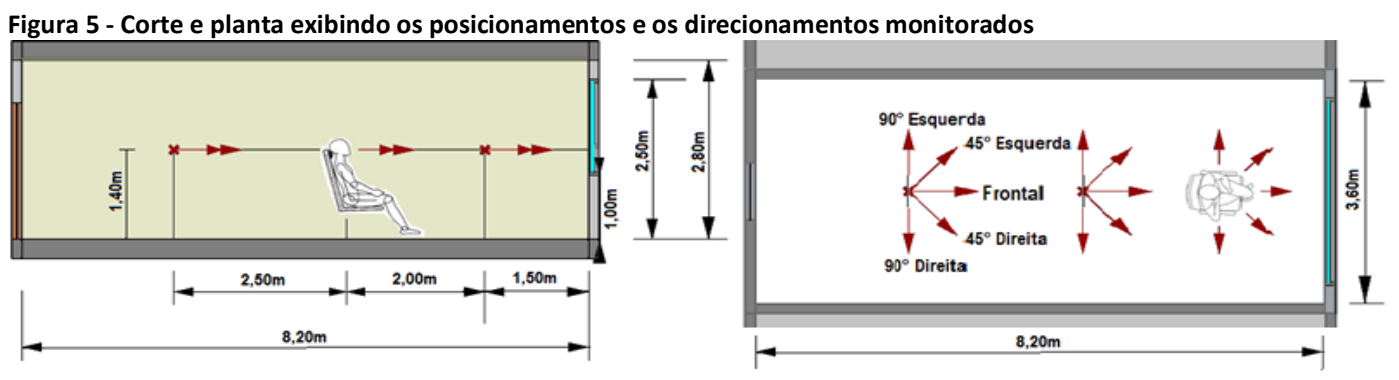

Fonte: Os autores.

\section{Simulação da probabilidade de ofuscamento}

Nessa pesquisa o DGP é escolhido como o indicador de ofuscamento. Para obtenção dos dados a função "Point-in-time-Glare" é acessada através do software de modelagem Rhinoceros 3D 5.0 e dos plug-ins Grasshopper 0.9 e DIVA 4.0 (RADIANCE). A ferramenta de avaliação do ofuscamento é submetida à rotina de simulação anual de 3650 horas. Logo, para cada posicionamento e direção de visão do observador, foram geradas as visualizações (renderizações), a faixa de desconforto apurada e os valores de DGP. As dimensões de cada imagem foram delimitadas em $600 \times 600$ pixels no modo câmera "olho-de-peixe" $\left(180^{\circ}\right)$, por este representar melhor o campo de visão do olho humano. As 60 combinações de posição (03), direção (05), e orientação solar (04), nas 3650 horas ocupadas, resultaram em 219.000 situações horárias registradas. Os principais parâmetros do RADIANCE utilizados são listados na Tabela 3.

Tabela 3 - Principais parâmetros do RADIANCE utilizados na simulação da probabilidade de ofuscamento

\begin{tabular}{ccc}
\hline Parâmetro & Nome do Parâmetro & Valor Utilizado \\
\hline -ar & ambient resolution & 128 \\
\hline -ad & ambient divisions & 1024 \\
\hline -as & ambient super-samples & 1024 \\
\hline -aa & ambient accuracy & 0,25 \\
\hline -ab & ambient bounces & 5 \\
\hline
\end{tabular}

Fonte: Os autores. 


\section{Simulação da radiação solar incidente}

O uso do DIVA na interface do Grasshopper possibilitou a obtenção das radiações solares horárias, direta e difusa, incidentes em todo o plano horizontal à altura do plano de tarefas, $0,8 \mathrm{~m}$ acima do piso. Este procedimento foi realizado através da função "Radiation Map". A partir de todos os sensores do grid do plano horizontal, com espaçamento de $0,5 \mathrm{~m}$, determinaram-se os valores respectivos a cada posição. À altura da face do observador $(1,4 \mathrm{~m})$ foram capturadas as radiações solares incidentes, a partir de um grid circular em cada posição, de 0,5 $\mathrm{m}$ de diâmetro, paralelo à janela.

\section{Tratamento e análise dos resultados}

Com relação à probabilidade de ofuscamento, os dados horários foram organizados em frequências anuais dos níveis de percepção de acordo com a orientação solar, a posição e o direcionamento do ocupante. De modo semelhante, foi realizado o comparativo dos perfis anuais dos níveis de DGP. Um limite de tolerância de $5 \%$ do tempo com níveis intoleráveis foi aplicado aos 60 cenários anuais, para indicar os mais críticos. Este seria, segundo a norma EN 17037 (CEN, 2017), um nível mínimo de proteção ao ofuscamento.

Em relação à radiação solar incidente (direta e difusa), os dados horários possibilitaram a elaboração de frequências de radiação direta e dos perfis anuais. Estes puderam ser comparados em função da posição do ocupante e da orientação solar do ambiente.

Considerando que o valor de $50 \mathrm{~W} / \mathrm{m}^{2}$ de radiação solar direta é capaz de causar desconforto térmico ou visual quando atinge o ocupante (Reinhart, 2004), as frequências anuais de radiação solar direta superior a $50 \mathrm{~W} / \mathrm{m}^{2}$ foram registradas, tanto no plano horizontal quanto na face, para cada posição monitorada. Aplicando também uma tolerância de $5 \%$ do tempo com insolação acima da indesejada é possível delimitar os cenários que atingiram um nível de exposição solar anual excessiva.

$\mathrm{Na}$ análise conjunta, as ocorrências indesejadas com base na probabilidade de ofuscamento e na insolação são comparadas. Os valores horários de DGP e de radiação solar (direta e difusa) são correlacionados com o intuito de indicar o grau de correlação.

\section{Resultados e discussão}

Os dados horários de probabilidade de ofuscamento (DGP) e de radiação solar direta e difusa foram submetidos às análises temporais e apresentados nas seguintes subseções.

\section{Probabilidade de ofuscamento}

As frequências dos valores de probabilidade de ofuscamento (DGP), seguindo as faixas de percepção, foram registradas em função da direção de visão, da orientação e da posição do observador, como apresentado na Figura 6. Foi confirmado o decréscimo drástico dos níveis intoleráveis e desconfortáveis advindo da rotação da visão (frontal para paralela à janela) e do distanciamento da janela. Confirma-se pelas frequências que o ocupante situado a $1,5 \mathrm{~m}$ da janela é submetido à situação mais crítica. Porém quando se afasta $2 \mathrm{~m}$ da janela, as condições intoleráveis são reduzidas até $63 \%$, enquanto que, na mesma posição, com a rotação de $90^{\circ}$ no direcionamento, atingiram-se reduções de até $74 \%$ da frequência anual intolerável. Isto indica que não é preciso inutilizar espaços próximos à abertura. A rotação do lay-out pode possibilitar o aproveitamento do espaço. Dos 60 cenários anuais simulados, 19 atingiram frequência de desconforto intolerável superior a 5\%. Dentre estes, 14 se encontram na posição $1,5 \mathrm{~m}$ e os demais na posição $3,5 \mathrm{~m}$. Dentre as 60 possibilidades de projeto, 1/3 deve receber atenção em relação ao desconforto visual. 
GARCIA, Dayan de L. R.; PEREIRA, Fernando O. R.

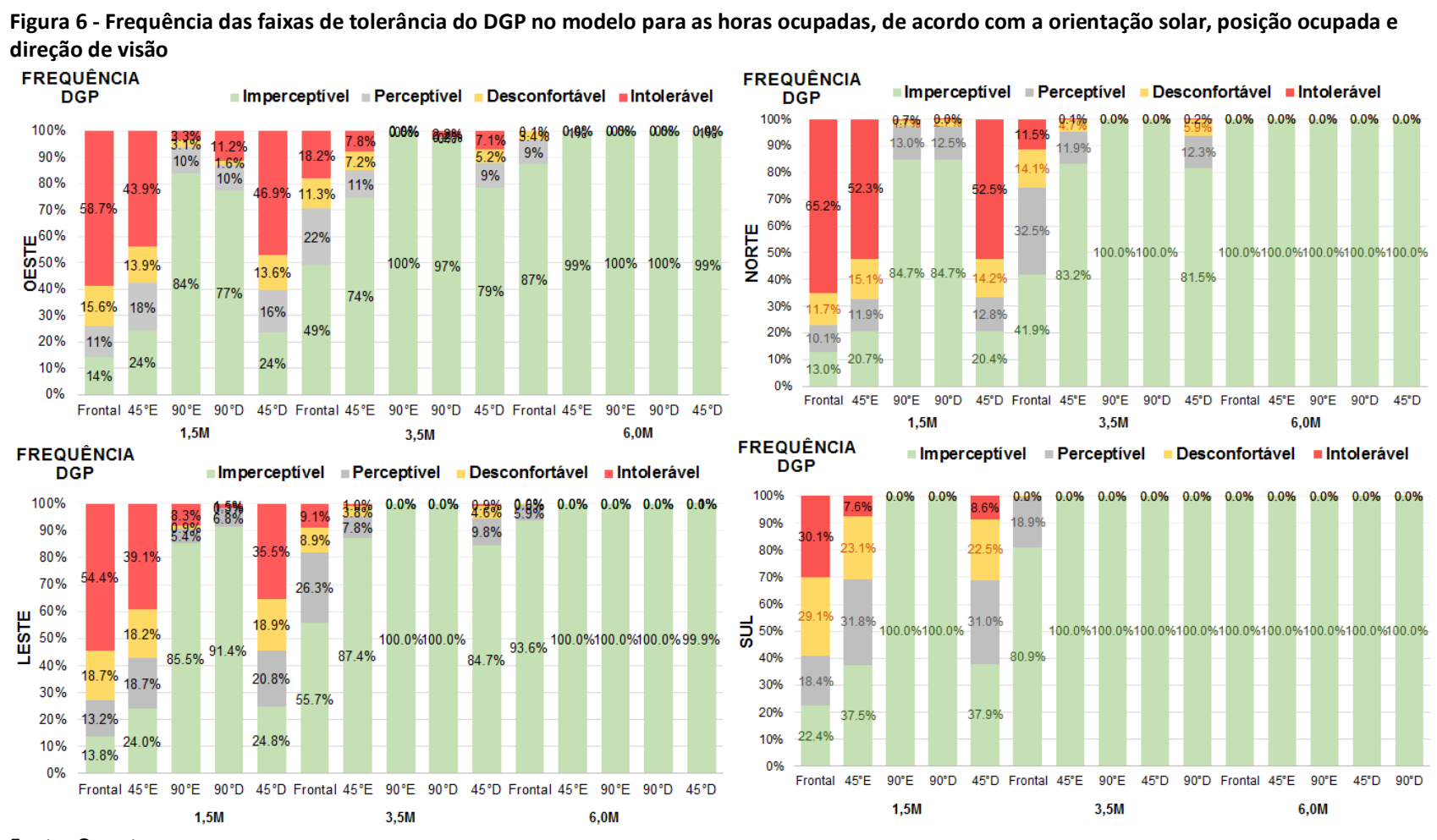

Fonte: Os autores.

$\mathrm{Na}$ análise dos perfis anuais de probabilidade de ofuscamento (Figura 7 e Figura 8) foi possível observar como se distribuem as frequências desconfortáveis e intoleráveis no decorrer dos meses do ano e das horas do dia e o limiar entre conforto e desconforto. Foi possível identificar que de setembro a abril, na posição $1,5 \mathrm{~m}$ e visão frontal, não há distinção entre as orientações. Entretanto, na mesma posição a $90^{\circ}$ à direita ou à esquerda, as orientações solares apresentam níveis intoleráveis completamente distintos. Neste caso as horas de DGPintolerável, para a orientação Leste, se concentraram de fevereiro a outubro das $8 \mathrm{~h}$ às $9 \mathrm{~h}$. Na orientação Norte as ocorrências indesejadas se concentraram em Junho das $12 \mathrm{~h}$ às $16 \mathrm{~h}$ e na orientação Oeste de outubro a fevereiro das $16 \mathrm{~h}$ às $17 \mathrm{~h}$. Isto implica em recomendar controle solar dinâmico na orientação Norte e Oeste, enquanto que na orientação Leste um controle solar estático, como brises devidamente dimensionados e inclinados, pode reduzir o desconforto visual durante todo o ano em um horário específico.

Foi identificada uma semelhança entre o direcionamento $45^{\circ}$ à esquerda com o direcionamento $45^{\circ}$ à direita. Entretanto, os direcionamentos $90^{\circ}$ à esquerda e $90^{\circ}$ à direita apresentaram diferenças na distribuição dos níveis intoleráveis e desconfortáveis. Isto se deve ao fato destas posições paralelas à janela serem menos influenciadas pelo céu visível e mais por reflexões nas paredes internas. Na orientação Leste, se o ocupante a $1,5 \mathrm{~m}$ da janela, direcionado $90^{\circ}$ à esquerda, alterar seu direcionamento para $90^{\circ}$ à direita, os níveis intoleráveis que o atingem entre $8 \mathrm{~h}$ e $9 \mathrm{~h}$ de fevereiro a outubro desaparecerão, ao custo de alguns momentos intoleráveis em dezembro, janeiro e fevereiro. Entretanto, se a mesma mudança for realizada para um ocupante situado no modelo orientado para Oeste, os níveis desconfortáveis vivenciados de outubro a fevereiro das $16 \mathrm{~h}$ às $17 \mathrm{~h}$ desaparecerão, enquanto que de fevereiro a outubro das $15 \mathrm{~h}$ às $17 \mathrm{~h}$ será um período muito marcado por $\mathrm{DGP}_{\text {intolerável. }}$ Pode-se observar então que a simples alteração de $180^{\circ}$ no direcionamento do ocupante, em seu posto de tarefa, pode culminar em níveis e momentos de desconforto visual totalmente distintos. 
GARCIA, Dayan de L. R.; PEREIRA, Fernando O. R.

Análise da exposição ao ofuscamento e à insolação em ambiente de uso

Figura 7 - Perfis anuais de probabilidade de ofuscamento para a posição a 1,5m da janela, nas direções de visão e orientações solares investigadas

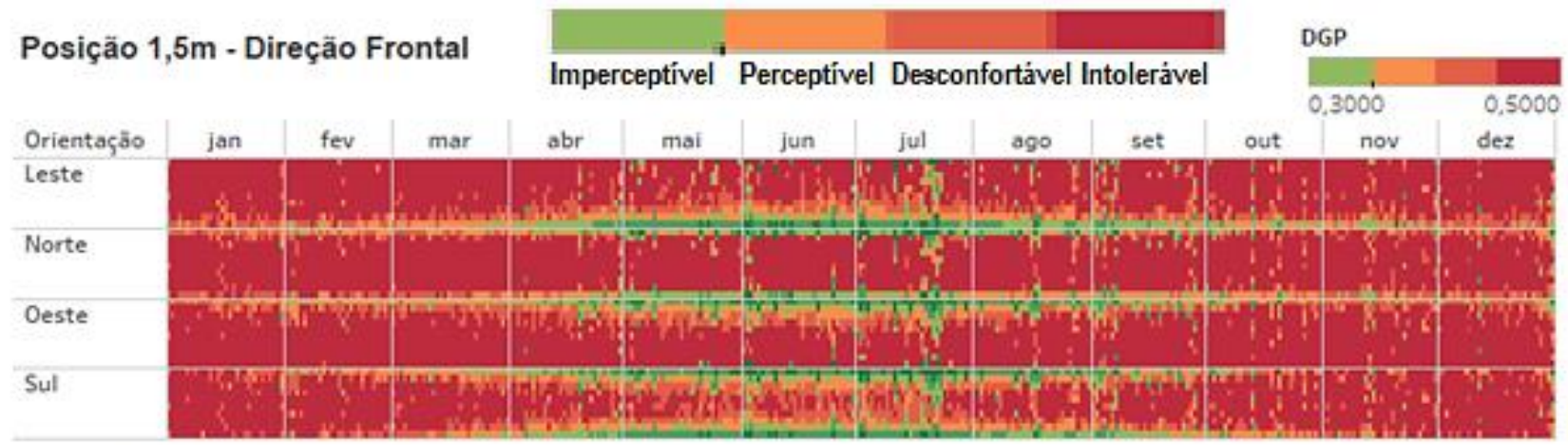

Posição $1,5 \mathrm{~m}$ - Direçäo $45^{\circ}$ Esquerda

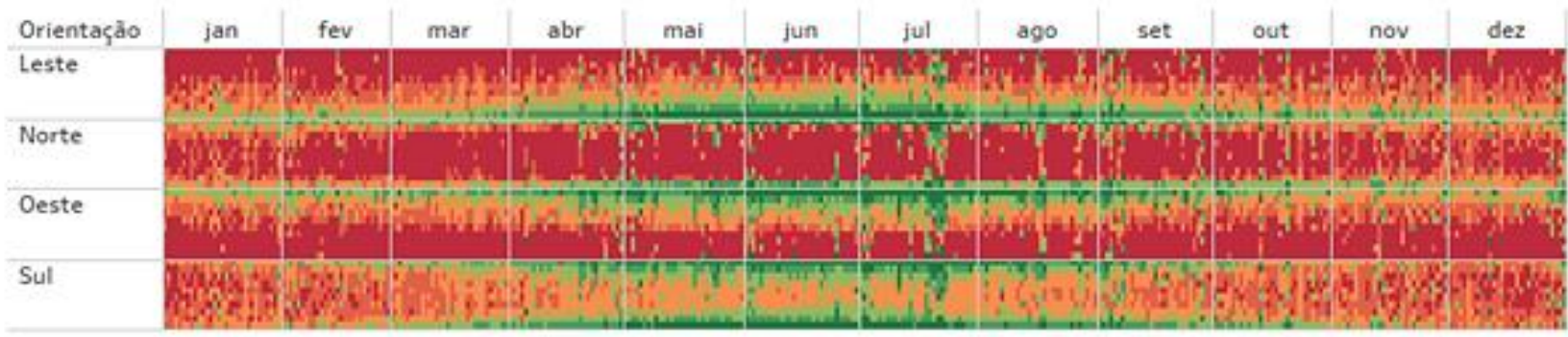

Posiçăo $1,5 \mathrm{~m}$ - Direção $90^{\circ}$ Esquerda

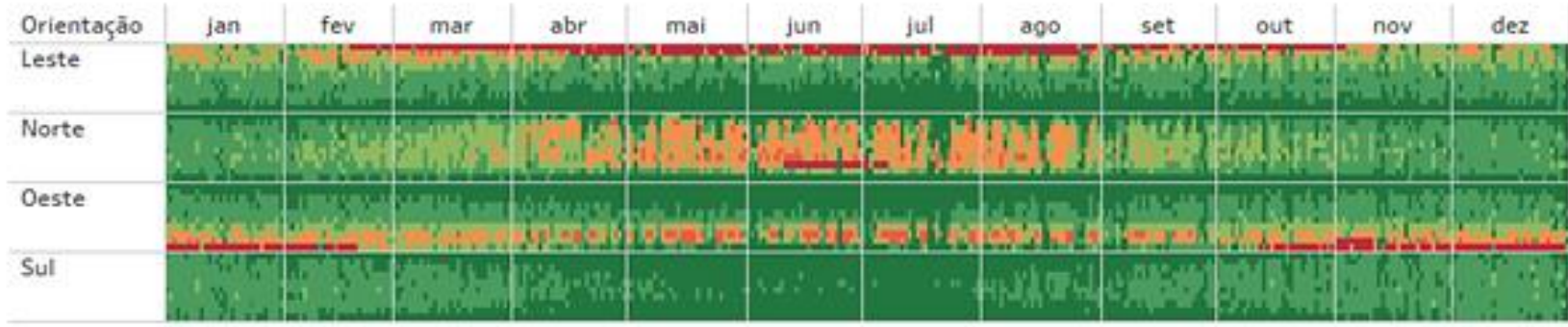

Posiçäo $1,5 \mathrm{~m}$ - Direçăo $90^{\circ}$ Direita

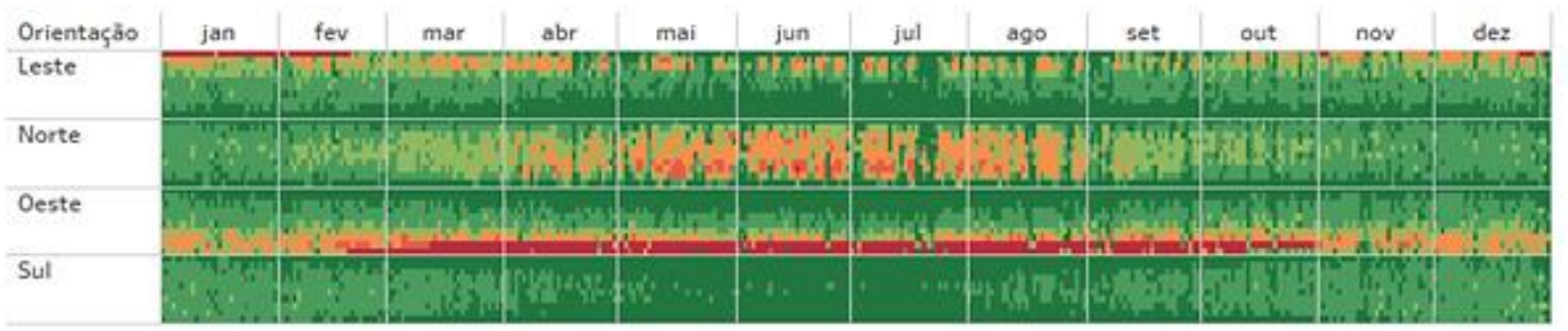

Posição $1,5 \mathrm{~m}$ - Direçäo $45^{\circ}$ Direita

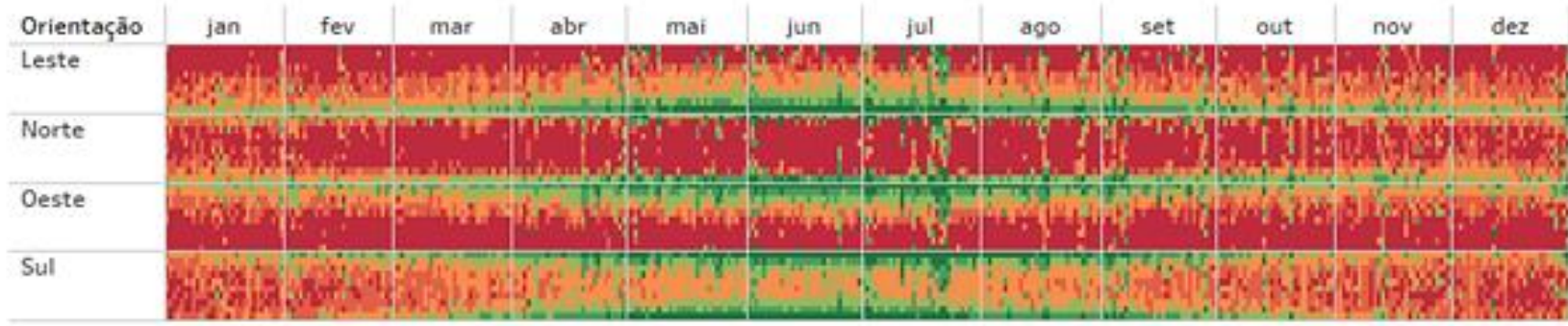

Fonte: Os autores. 
GARCIA, Dayan de L. R.; PEREIRA, Fernando O. R.

Análise da exposição ao ofuscamento e à insolação em ambiente de uso

Figura 8 - Perfis anuais de probabilidade de ofuscamento para as direções de visão e orientações solares investigadas na posição a 3,5m da janela

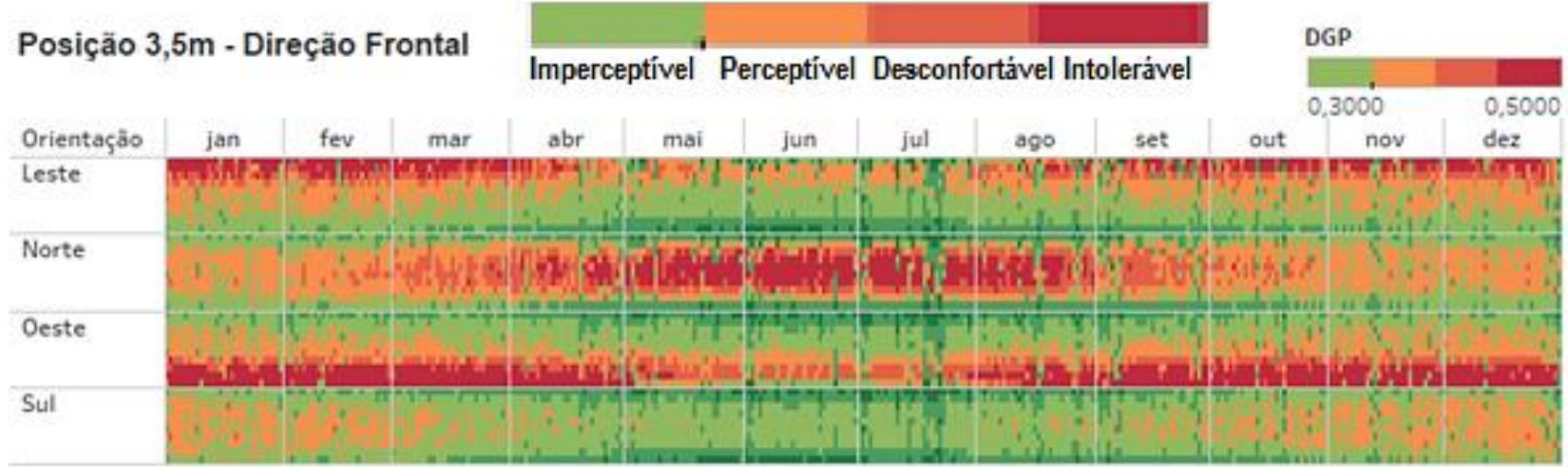

\section{Posiçäo $3,5 \mathrm{~m}$ - Direçäo $45^{\circ}$ Esquerda}

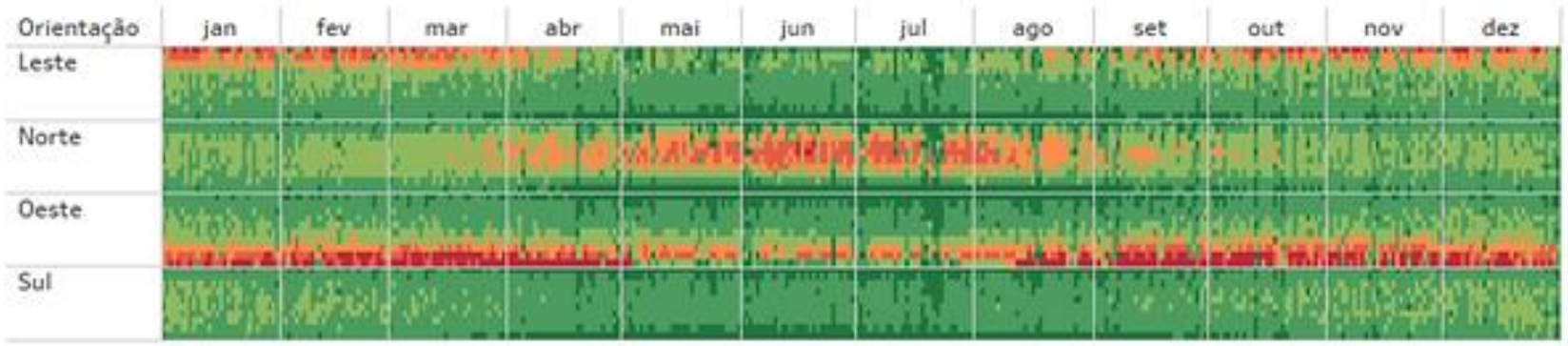

Posição 3,5m - Direção $90^{\circ}$ Esquerda

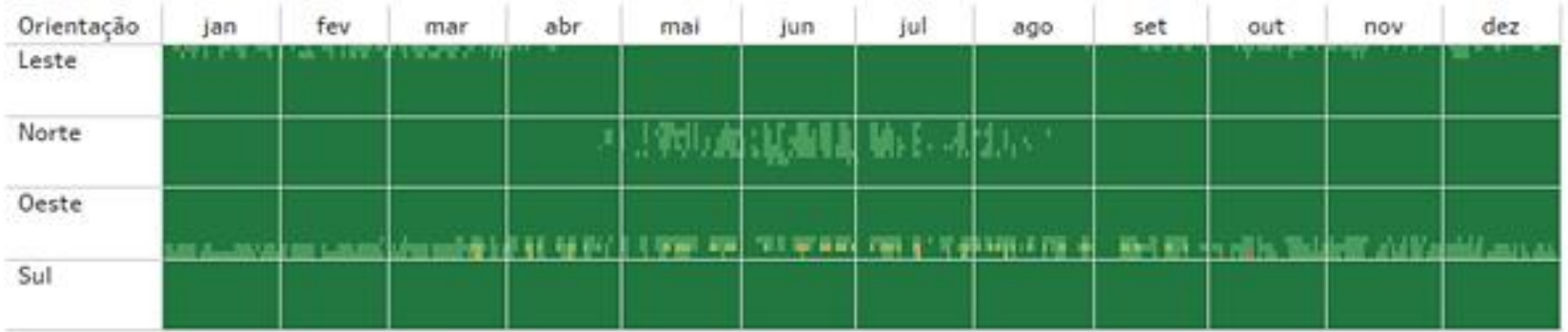

Posição $3,5 \mathrm{~m}$ - Direçäo $90^{\circ}$ Direita

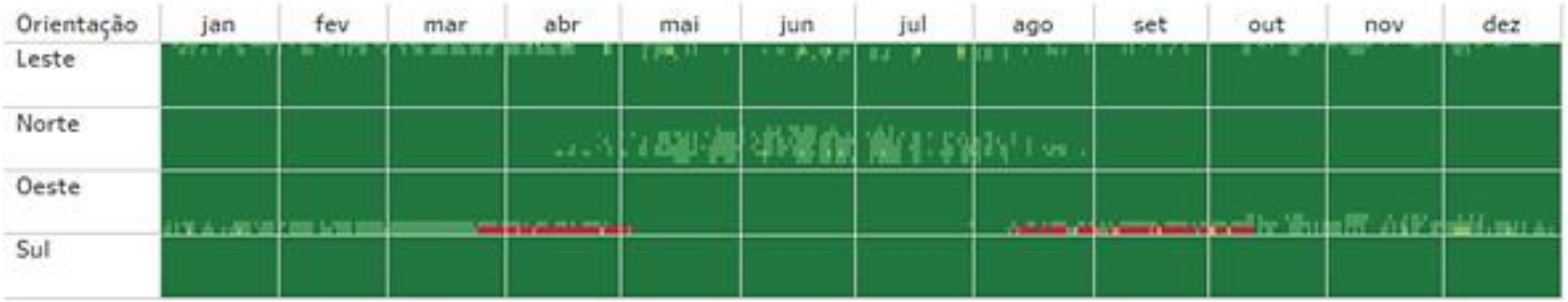

\section{Posiçäo $3,5 \mathrm{~m}$ - Direçäo $45^{\circ}$ Direita}

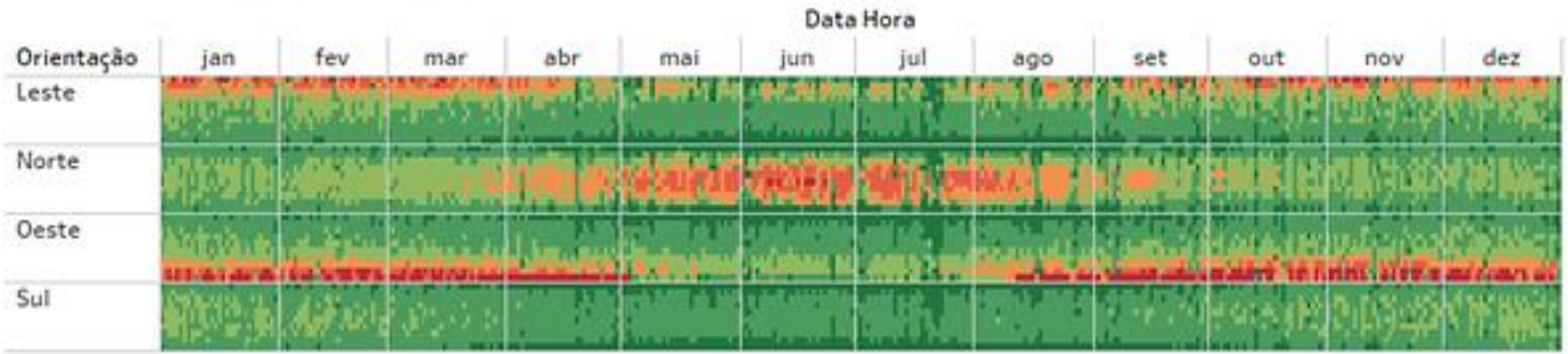

Fonte: Os autores. 


\section{Radiação solar incidente}

O comparativo de frequências anuais apresentado através da Figura 9 identifica que, no plano horizontal ( $0,8 \mathrm{~m}$ ), apenas na posição 1,5 m e nas orientações Norte, Leste e Oeste se apresentaram frequências anuais de insolação superior à tolerância de $5 \%$ do tempo. Nessas orientações o ocupante na posição 1,5 m está suscetível em receber insolação considerada indesejada, durante aproximadamente $1 / 5$ do tempo de uso. Nas posições 3,5 m e 6,0 m obtiveram-se frequências de radiação solar direta apenas na orientação Oeste devido à penetração dos raios solares ao final da tarde nas regiões mais profundas do ambiente. Na posição 3,5 m, mesmo com frequência anual abaixo de $5 \%$ pode implicar necessidade de controle, principalmente pelo fato dos momentos de insolação nesta posição corresponder com momentos de sol aparente no campo visual do observador, condição de impreterível desconforto visual.

Quando se analisa as frequências de insolação que atinge a região da face do ocupante $(1,4 \mathrm{~m})$, conforme Figura 9, são observadas frequências próximas ao plano horizontal apenas para o ambiente orientado a Oeste e o ocupante nas posições 1,5 m e 3,5 m. As frequências de insolação na face para as orientações Leste e Norte apresentaram valores inferiores ao plano horizontal $(0,8 \mathrm{~m})$, devido à trajetória solar combinada à diferença de altura e diferença do ângulo de incidência solar entre o plano vertical e o plano horizontal. A captura na altura da face pode ocultar as incidências abaixo, principalmente nas regiões mais próximas à abertura. Porém, nas regiões profundas o plano vertical registrou mais ocorrências de radiação solar acima da tolerada.

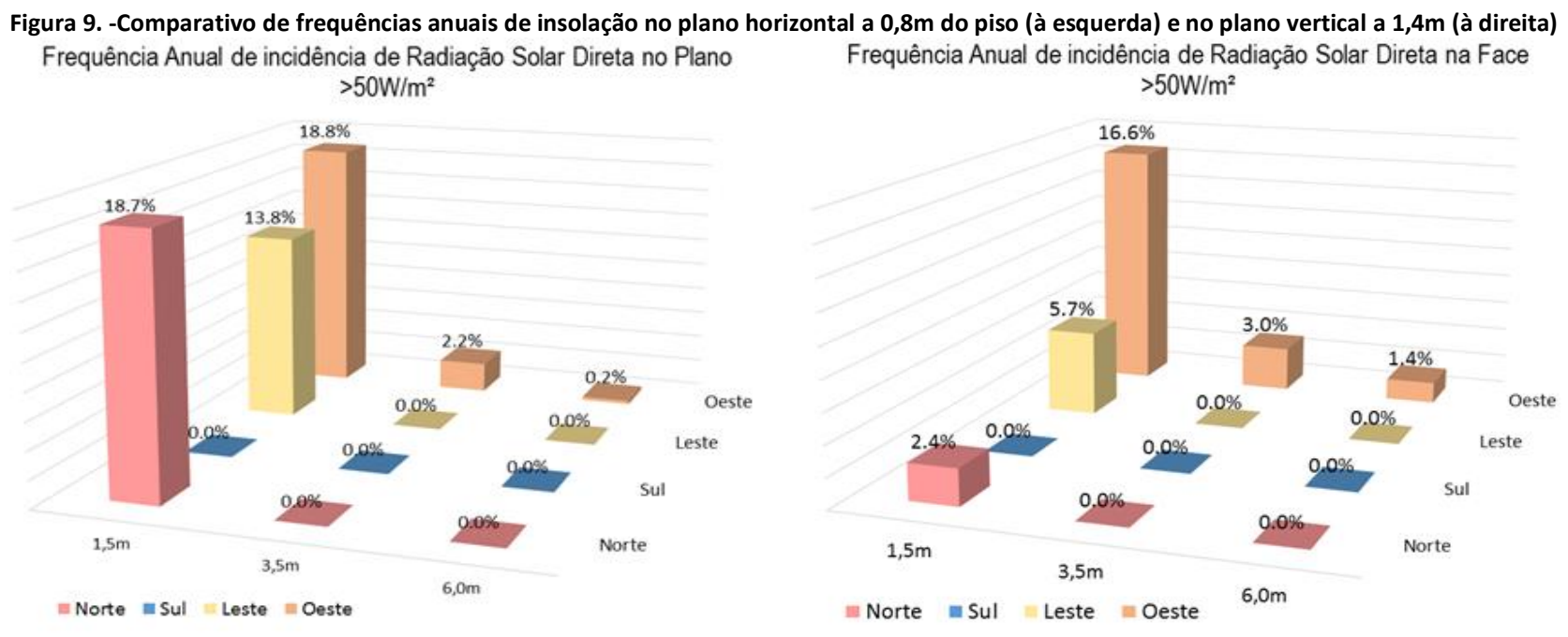

Fonte: Os autores.

Os perfis anuais de irradiação foram comparados de acordo com a orientação solar, a posição ocupada e a parcela da radiação total, conforme disposto na Figura 10. Devido ao baixo conteúdo radiante incidente na posição $6,0 \mathrm{~m}$ e no ambiente orientado para 0 Sul, os demais perfis não foram apresentados. A partir dessa ferramenta verificou-se, para a orientação Leste, incidência de radiação direta entre $8 \mathrm{~h}$ e $10 \mathrm{~h}$ na posição $1,5 \mathrm{~m}$ durante todo o ano, mas os valores mais elevados se concentraram de setembro a abril. Enquanto na orientação Oeste a incidência solar direta nessa posição $(1,5 \mathrm{~m})$ se inicia por volta das $14 \mathrm{~h}$ e termina entre $16 \mathrm{~h}$ e $18 \mathrm{~h}$, durante todo o ano. Assim como na orientação Leste, no inverno as radiações diretas são mais baixas. No ambiente orientado para o Norte é observada a incidência direta apenas na posição 1,5 $\mathrm{m}$ das $10 \mathrm{~h}$ às $16 \mathrm{~h}$, nos meses de março a setembro. Isto evidencia a menor altura solar na localidade nesse período. 
GARCIA, Dayan de L. R.; PEREIRA, Fernando O. R.

Análise da exposição ao ofuscamento e à insolação em ambiente de uso

Figura 10 - Perfis anuais de incidência de radiação solar no plano horizontal (0,8 m), nas posições e orientações monitoradas (1,5 m e 3,5 m)
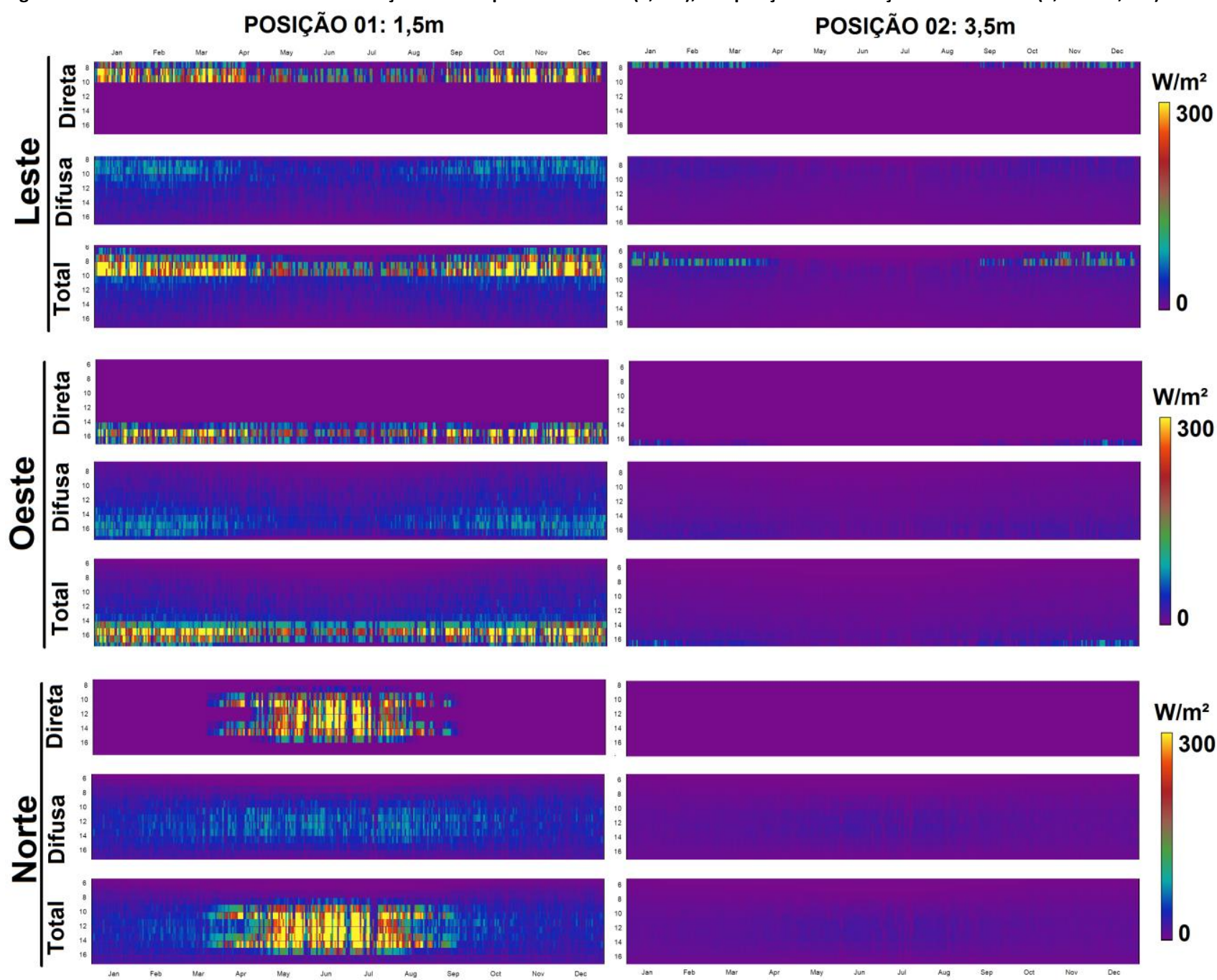

Fonte: Os autores.

Probabilidade de ofuscamento vs. Insolação

As frequências anuais de $D G P_{\text {intolerável }}$ e $D G P_{\text {desconfortável foram comparadas com as }}$ frequências anuais de insolação indesejada (radiação solar direta $>50 \mathrm{~W} / \mathrm{m}^{2}$ ). Para o ocupante com direção frontal e a $45^{\circ}$ da frontal, atingiram-se mais horas indesejadas. Entretanto, para a posição $1,5 \mathrm{~m}$ com os direcionamentos paralelos à janela $\left(90^{\circ}\right)$, os resultados de probabilidade de ofuscamento foram inferiores às frequências de insolação no plano horizontal, principalmente na orientação Norte. Entretanto, as frequências da insolação no plano vertical demonstraram mais correspondência com os níveis de desconforto captados nas vistas paralelas à abertura.

Os perfis anuais de DGP para a posição $1,5 \mathrm{~m}$ e direção $90^{\circ}$ à direita foram os únicos que atingiram semelhança com os perfis de radiação solar total. Neste cenário esses dois comportamentos corresponderam entre si melhor que os demais. Na posição 3,5 m e mesma direção de visão observaram-se semelhanças, embora os níveis de DGP e de radiação solar permaneceram baixos.

O valor de $50 \mathrm{~W} / \mathrm{m}^{2}$ estipulado para representar a insolação indesejada pode ser considerado baixo, se comparado com outros valores investigados (VAN DEN WYMELENBERG, 2012). Isto resultaria em muitas horas apuradas como desconfortáveis, mas nesta pesquisa este valor se demonstrou mais brando que o $\mathrm{DGP}_{\text {intolerável. }}$ 
Foram realizadas correlações lineares entre os valores horários de DGP e as radiações solares direta e difusa capturadas no plano horizontal a $0,8 \mathrm{~m}$ e no plano vertical a 1,4 $\mathrm{m}$. No geral, foram obtidos baixos valores de $R^{2}$, caracterizando baixo grau de correlação. A correlação logarítmica resultou em menor grau, se comparado à linear. $O$ maior valor de $R^{2}(0,6956)$ foi atingido na correlação linear entre o DGP frontal e a radiação difusa na face, para o ocupante na posição 3,5 $\mathrm{m}$ e orientação solar Leste. Como demonstrado na Figura 10, o maior $R^{2}$ obtido para a relação do DGP frontal com a radiação solar direta no plano horizontal foi de 0,3496. Os maiores valores de $R^{2}$ atingidos nas correlações entre a radiação solar direta e o DGP foram de 0,3669, para a orientação Leste e direção $90^{\circ}$ à esquerda e 0,3732 para orientação Oeste e direção $90^{\circ}$ à direita (Figura 10). Estes resultados evidenciam a melhor correspondência da radiação solar direta na face com o DGP, em relação à radiação direta plano horizontal.

Figura 10 - Correlação dos valores horários de DGP e de Radiação Solar Direta e Difusa
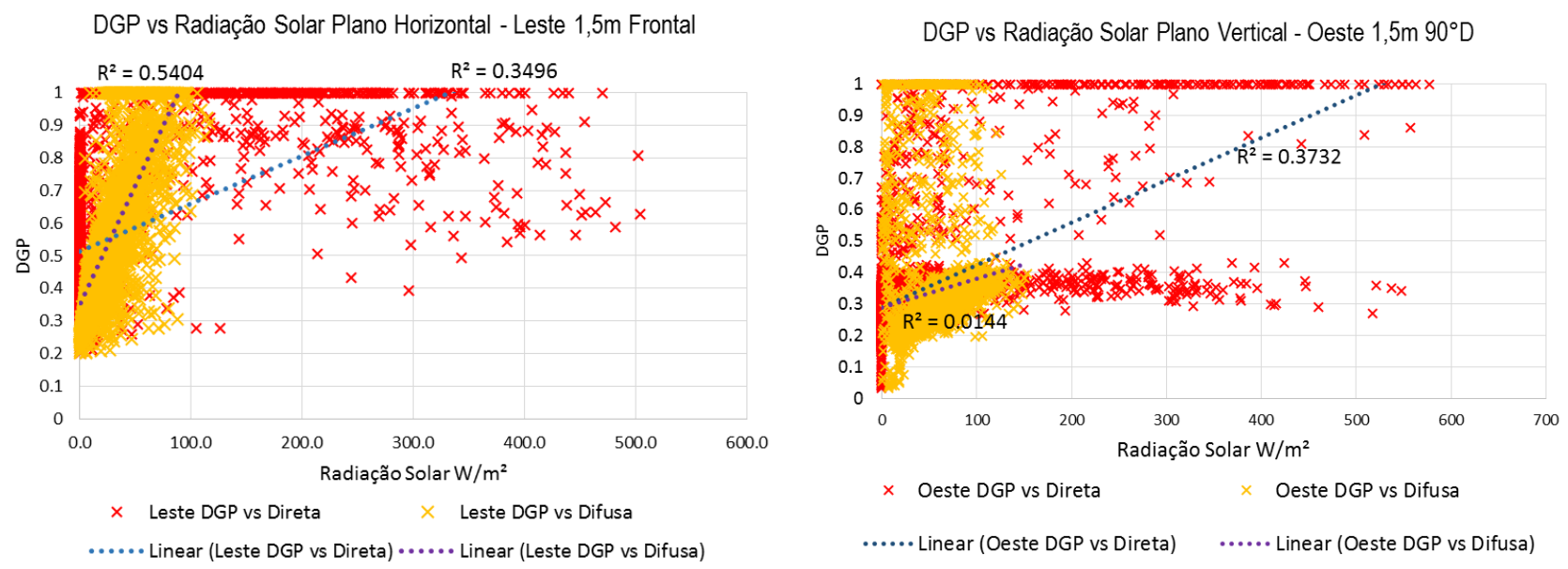

Fonte: Os autores.

Para as posições 3,5 m e 6,0 m, a maioria das correlações entre o DGP e a radiação solar direta resultaram em zero, devido à falta de ocorrência de insolação nessas posições, exceto para o ambiente orientado para Oeste. Por outro lado, as radiações difusas, por sofrerem influência da distribuição interna da luz, apresentaram melhores correlações com o DGP, mesmo não atingindo graus significativos de correlação $\left(R^{2}>0,90\right)$.

\section{Conclusão}

Nessa pesquisa foram analisados quantitativamente os níveis de probabilidade de ofuscamento e de insolação para um ocupante em 60 situações diferentes, envolvendo características consideradas no projeto de edificações. Por meio da modelagem e simulação computacional de edificações, ferramenta científica válida nas pesquisas de arquitetura e engenharia, o ocupante foi considerado em uma sala de uso diurno prolongado ( 8 hoo às 17hoo), em 03 posições e 05 direções de visão. Esse módulo representativo de edifícios de múltiplos pavimentos foi orientado para Leste, Oeste, Norte e Sul e situado em Florianópolis-SC.

Para a avaliação dos níveis de probabilidade de ofuscamento, o indicador adotado, Daylight Glare Probability (DGP), conseguiu demonstrar diferenças de até $74 \%$, no tempo de desconforto visual entre a vista frontal e as paralelas à janela. Porém, na posição 1,5 $\mathrm{m}$ os direcionamentos diagonais à janela $\left(45^{\circ}\right)$ não resultaram em reduções inferiores à tolerância recomendada ( $f D G P_{\text {intolerável }<5 \%}$ tempo). 
Estes resultados confirmaram a vulnerabilidade ao ofuscamento para ocupantes próximos às aberturas, mas demonstraram que isto não inviabiliza o uso destes espaços, desde que cuidados no projeto possam promover proteção. O lay-out interno pensado com base no direcionamento do ocupante paralelo à abertura pode ser a recomendação mais evidente, tanto neste trabalho quanto em outros da área (JAKUBIEC; REINHART, 2012). No entanto, os resultados atingidos confirmam que, mesmo nessa configuração, são presentes frequências de desconforto acima da recomendada e, consequentemente, existe a necessidade de controle solar. Em contrapartida, os resultados atestam que combinando a posição ocupada, a direção de visão e a orientação solar, é possível projetar lay-outs que não necessariamente insiram os ocupantes orientados com vista paralela à janela.

Mediante as características atribuídas ao envelope e ao ocupante, na posição 3,5 $\mathrm{m}$ foi observado este limiar entre cenários anuais de conforto ou desconforto visual. Foram apontadas 13 situações com frequências anuais de DGP intolerável e DGP $P_{\text {desconfortável abaixo }}$ da tolerância de $5 \%$ de ocorrência, enquanto 07 apresentaram valores superiores, conforme dois níveis de proteção recomentados pela EN 17037:2017. Recomenda-se a aplicação desta verificação para outras cidades brasileiras, com o intuito de se apurar diferenças nas necessidades de proteção ao ofuscamento e à insolação. Não obstante, outras características das aberturas devem ser investigadas, como outros valores de PAF e a presença de elementos de controle solar. Com isto, serão consolidadas mais alternativas de proteção aplicáveis em projetos de arquitetura e engenharia.

Em relação à exposição dos ocupantes à insolação, através da frequência de radiação solar direta maior que $50 \mathrm{~W} / \mathrm{m}^{2}$ e dos perfis anuais de radiação solar incidente, foi possível identificar o quanto a posição mais próxima da janela é mais vulnerável em relação às demais investigadas. $A 1,5 \mathrm{~m}$, quase $1 / 5$ do tempo de uso é comprometido com a insolação indesejada. No plano horizontal a $0,8 \mathrm{~m}$ as frequências de insolação foram maiores que no plano da face $(1,4 \mathrm{~m})$, com exceção das posições 3,5 $\mathrm{m}$ e 6,0 $\mathrm{m}$ na orientação Oeste. Isto demonstrou que monitorar a incidência no plano horizontal da tarefa é considerada uma medida mais restritiva em relação à proteção dos ocupantes. No entanto, ao longo da profundidade do ambiente orientado para Leste ou Oeste, a região da face fica mais suscetível à incidência direta ao início e final do dia.

Os perfis anuais de radiação solar incidente permitiram delimitar os horários críticos do dia e os meses do ano em que os ocupantes podem desejar o controle da luz natural. Consequentemente, o momento dessa necessidade combinado à forma de controle podem alterar o ambiente luminoso e o térmico pelo restante do dia, adequando-os em alguns aspectos, mas podendo comprometê-los em outros. Neste âmbito, os valoresalvos que representam os aspectos desconfortáveis são os responsáveis por garantir boas inferências nos projetos e confiabilidade nos algoritmos de controle. Sendo assim, a radiação solar direta estipulada para representar a insolação indesejada (>50 W/m²), baseada em estudos no hemisfério Norte, deve ser questionada como adequada por meio de investigações in situ em cidades brasileiras. Além disso, recomenda-se aplicar, para outras localidades, as simulações computacionais e as correlações empregadas.

Em relação às correlações lineares da probabilidade de ofuscamento com a incidência de radiação solar, foram gerados somente valores de $\mathrm{R}^{2}$ abaixo do significativo. No entanto, foi possível comprovar a maior proximidade entre a radiação solar na face e o DGP na configuração paralela à janela. Embora não significativas, as correlações apontaram que a influência exercida por cada componente solar (direta e difusa) é variável de acordo com a posição ocupada e direção de visão. Além disso, quando as duas são equilibradamente responsáveis pelo DGP apurado, a radiação solar total se correlaciona melhor que cada parcela isolada. 


\section{Agradecimentos}

Agradecimentos ao Laboratório de Conforto Ambiental da Universidade Federal de Santa Catarina e ao Programa de Pós-Graduação em Arquitetura e Urbanismo da Universidade Federal de Santa Catarina. O presente trabalho foi realizado com apoio da Coordenação de Aperfeiçoamento de Pessoal de Nível Superior - Brasil (CAPES).

\section{Referências}

ABNT - ASSOCIAÇÃO BRASILEIRA DE NORMAS TÉCNICAS. NBR 15220: Desempenho térmico de Edificações. Parte 3 - Zoneamento bioblimático brasileiro. Rio de Janeiro, 2005.

ABNT - ASSOCIAÇÃO BRASILEIRA DE NORMAS TÉCNICAS. NBR 15215: lluminação Natural: Partes 1-4. Rio de Janeiro, 2005 a.

ABNT - ASSOCIAÇÃO BRASILEIRA DE NORMAS TÉCNICAS. NBR ISO/CIE 8995: lluminação em ambientes de trabalho: Parte 1 - Interior. Rio de Janeiro, 2013.

CHAUVEL, P.; COLLINS, J.B.; DOGNIAUX, R. Glare from windows: current views of the problem. Lighting Research and Technology. v. 14, p. 31-46, 1982. DOI: https://doi.org/10.1177\%2F096032718201400103

CARLETTI, C.; SCIURPI, F.; PIERANGIOLI, L. The energy upgrading of existing buildings: Window and shading device typologies for energy efficiency refurbishment. Sustainability (Switzerland), v. 6, n. 8, p. 5354-5377, 2014.

CEN - EUROPEAN COMMITTEE FOR STANDARDZATION. EN:17.037 - Daylighting in buildings. European Normative Draft. Denmark, 2017.

COLLINS, Belinda. Windows and people: A literature survey: psychological reaction to environments with and without windows. Washington: National Bureau of Standards, 1975. 100 p. (Building Science Series 70). Disponível em: https://nvlpubs.nist.gov/nistpubs/Legacy/BSS/nbsbuildingscience70.pdf. Acesso em: 23 mar. 2020.

DOE - DEPARTMENT OF ENERGY OF THE UNITED STATES. Arquivos climáticos válidos disponíveis: Arquivos climáticos disponibilizados na biblioteca do programa EnergyPlus. 2020. Weather Data to EnergyPlus. Disponível em: https://energyplus.net/weather. Acesso em: 23 mar. 2020..

GALASIU, A. D.; VEITCH, J. A. Occupant preferences and satisfaction with the luminous environment and control systems in daylit offices: a literature review. Energy and Buildings, v. 38, n. 7, p. 728-742, 2006.

DOI:https://doi.org/10.1016/j.enbuild.2006.03.001

GOEDERT, G. S. Influência do uso de elementos de controle solar na probabilidade de ofuscamento, no ganho de calor solar e na iluminação natural. 204f. Dissertação (Mestrado) - Programa de Pós-graduação em Engenharia Civil, Universidade Federal de Santa de Catarina, 2017.

GOULART, C. "Janela" - elemento do ambiente construído. uma abordagem psicológica da relação "homemjanela'. Dissertação (Mestrado) - Programa de Pós-graduação em Engenharia de Produção, Universidade Federal de Santa Catarina, 1997.

HOPKINSON, R. G. Glare from daylighting in Buildings. Applied Ergonomics, v. 3.4, n. December, p. 206-215, 1972. DOI: https://doi.org/10.1016/0003-6870(72)90102-0

IESNA - ILLUMINATING ENGINEERING SOCIETY OF NORTH AMERICA. Lighting Measurement \#83: Spatial Daylight Autonomy (sDA) and Annual Sunlight Exposure (ASE). 1 ed. New York: Daylight Metrics Committee, 2012. 19 p.

JAKUBIEC, J. A.; REINHART, C. F. The "adaptive zone" - A concept for assessing discomfort glare throughout daylit spaces.pdf. Lighting Research and Technology, v. 44, p. 149-170, 2012.

DOI:https://doi.org/10.1177\%2F1477153511420097 
JAKUBIEC, J. A.; REINHART, C. F.; VAN DEN WYMELENBERG, K.. Towards an integrated framework for predicting visual comfort conditions from luminance-based metrics in perimeter daylit spaces. In: CONFERENCE OF INTERNATIONAL BUILDING PERFORMANCE SIMULATION ASSOCIATION, 14., 2015, Hyderabad. Proceedings [...]. Hyderabad: IBPSA, 2015. p. 1186-1196.

KARLSEN, L. et al. Verification of simple illuminance based measures for indication of discomfort glare from windows. Building and Environment, v. 92, p. 615-626, 2015. DOI: http://dx.doi.org/10.1016/j.buildenv.2015.05.040

KONIS, K. Predicting visual comfort in side-lit open-plan core zones: Results of a field study pairing high dynamic range images with subjective responses. Energy and Buildings, v. 77, p. 67-79, 2014.

DOI:https://doi.org/10.1016/j.enbuild.2014.03.035

KONSTANTZOS, I.; TZEMPELIKOS, A. Daylight glare evaluation with the sun in the field of view through window shades. Building and Environment, v. 113, p. 65-77, 2017. DOI: https://doi.org/10.1016/j.buildenv.2016.09.009

LARSON, G. W.; SHAKESPEARE, R. Rendering with radiance: the art and science of lighting visualization. San Francisco: Morgan Kaufmann Publishers Inc., 1998.

MARDALJEVIC, J.; HESCHONG, L.; LEE, E. Daylight metrics and energy savings. Lighting Research and Technology, v. 41, n. 3, p. 261-283, 2009. DOI: https://doi.org/10.1177\%2F1477153509339703

MARKUS, T. A. The function of windows- A reappraisal. Building Science, v. 2, n. 2, p. 97-121, 1967. DOI:https://doi.org/10.1016/0007-3628(67)90012-6

MATOS, J. C. DA S. F.; SCARAZZATO, P. S. A iluminação natural no projeto de arquitetura: revisão sistemática da literatura. PARC Pesquisa em Arquitetura e Construção, v. 8, n. 4, p. 249-256, 2017. DOI:https://doi.org/10.20396/parc.v8i4.8650250

MCNEIL, A.; LEE, E. S. A validation of the Radiance three-phase simulation method for modelling annual daylight performance of optically complex fenestration systems. Journal of Building Performance Simulation, v. 6, n. 1, p. 24-37, 2012. DOI: https://doi.org/10.1080/19401493.2012.671852

NE'EMAN, E. Visual aspects of sunlight in buildings. Lighting Research \& Technology, v. 6, n. 3, p. 159-164, 1974. DOI: https://doi.org/10.1177\%2F096032717400600304

NEWSHAM, G. R. Manual Control of Window Blinds and Electric Lighting: Implications for Comfort and Energy Consumption. Indoor and Built Environment, v. 3, n. 3, p. 135-144, 1994. DOI:https://doi.org/10.1177\%2F1420326X9400300307

O'BRIEN, W.; KAPSIS, K.; ATHIENITIS, A. K. Manually-operated window shade patterns in office buildings: A critical review. Building and Environment, v. 60, p. 319-338, 2013. DOI: https://doi.org/10.1016/j.buildenv.2012.10.003

REINHART, C. F. Daylighting performance predictions. In: HENSEN, I.; LAMBERTS, R. (Eds.). Building Performance Simulation: for design and operation.1. ed, Abingdong: Routledge, 2018.

REINHART, C.; RAKHA, T.; WEISSMAN, D. Predicting the daylit Area - A comparison of students assessments and simulations at eleven schools of architecture. LEUKOS - Journal of Illuminating Engineering Society of North America, v. 10, n. 4, p. 193-206, 2014. DOI: https://doi.org/10.1080/15502724.2014.929007

REINHART, C. F.; JAKUBIEC, J. A.; IBARRA, D. Definition Of A Reference Office For Standardized Evaluations Of Dynamic Façade And Lighting Technologies. In: CONFERENCE OF INTERNATIONAL BUILDING PERFORMANCE SIMULATION ASSOCIATION, 13., 2035, Chambéry. Proceedings [...]. Chambéry: IBPSA, 2013. p. 3645-3652.

REINHART, C. F. Lightswitch-2002: A model for manual and automated control of electric lighting and blinds. Solar Energy, v. 77, n. 1, p. 15-28, 2004. DOI: https://doi.org/10.1016/j.solener.2004.04.003 
GARCIA, Dayan de L. R.; PEREIRA, Fernando O. R.

Análise da exposição ao ofuscamento e à insolação em ambiente de uso

RUBIN, A. I.; COLLINS, B. L.; TIBBOTT, R. L. Window blinds as a potential energy saver-a case study. NBS Building Science Series 112, Washington: U.S. DEPARTMENTE OF COMMER, 1978. 89 p.

STAZI, F. et al. Comparison on solar shadings: Monitoring of the thermo-physical behaviour, assessment of the energy saving, thermal comfort, natural lighting and environmental impact. Solar Energy, v. 105, p. 512-528, 1 jul. 2014. DOI: https://doi.org/10.1016/j.solener.2014.04.005

SUK, J. Y.; SCHILER, M.; KENSEK, K. Development of new daylight glare analysis methodology using absolute glare factor and relative glare factor. Energy and Buildings, v. 64, p. 113-122, 2013.

DOI:https://doi.org/10.1016/j.enbuild.2013.04.020

VAN DEN WYMELENBERG, K. Patterns of occupant interaction with window blinds: A literature review. Energy and Buildings, v. 51, n. 2012, p. 165-176, 2012. DOI: https://doi.org/10.1016/j.enbuild.2012.05.008

VAN DEN WYMELENBERG, K.; INANICI, M. A critical investigation of common lighting design metrics for predicting human visual comfort in offices with daylight. LEUKOS - Journal of Illuminating Engineering Society of North America, v. 10, n. 3, p. 145-164, 2014. DOI: https://doi.org/10.1080/15502724.2014.881720

VAN DEN WYMELENBERG, K. G. Visual comfort, discomfort glare, and occupant fenestration control: Developing a research agenda. LEUKOS - Journal of Illuminating Engineering Society of North America, v. 10, n. 4, p. 207-221, 2014. DOI: https://doi.org/10.1080/15502724.2014.939004

WIENOLD, J.; CHRISTOFFERSEN, J. Evaluation methods and development of a new glare prediction model for daylight environments with the use of CCD cameras. Energy and Buildings, v. 38, n. 7, p. 743-757, 2006. DOI:https://doi.org/10.1016/j.enbuild.2006.03.017

YAO, J. Determining the energy performance of manually controlled solar shades: A stochastic model based cosimulation. Applied Energy, v.127, p.64-80, 2014. DOI: https://doi.org/10.1016/j.apenergy.2014.04.046

\section{${ }^{1}$ Dayan de Loyola Ramos Garcia}

Engenheiro Ambiental e Sanitarista. Mestrando em Arquitetura e Urbanismo no Programa de Pós-Graduação em Arquitetura e Urbanismo da Universidade Federal de Santa Catarina. Caixa Postal 476. Campus UFSC - Trindade, PósARQ/CTC, Florianópolis, SC, Brasil, CEP88040-900.

\section{${ }^{2}$ Fernando Oscar Ruttkay Pereira}

Engenheiro Civil. PhD. Professor Titular do Departamento de Arquitetura e Urbanismo da Universidade Federal de Santa Catarina. Caixa Postal 476. Campus UFSC - Trindade, PósARQ/CTC, Florianópolis, SC, Brasil, CEP88040-900. 